ОСОБЕННОСТИ МАРКЕТИНГОВЫХ ПРОЦЕССОВ НА БАЗЕ ЦИФРОВИЗАЦИИ И УБЕРИЗАЦИИ ТУРИСТИЧЕСКОГО БИЗНЕСА

\title{
Zarubina U.V. \\ FEATURES OF MARKETING PROCESSES BASED ON DIGITALIZATION AND UBERIZATION OF THE TOURISM BUSINESS
}

\footnotetext{
Аннотация. Статья посвящена вопросам маркетинга мобильного приложения в области туризма.

Ключевые слова: туристический бизнес, мобильные приложения, маркетинг, обратная связь, LTV, лояльность клиентов.

Abstract. The article is devoted to the marketing of mobile applications in the field of tourism.

Keywords: travel business, mobile apps, marketing, feedback, LTV, customer loyalty.
}

Одним из направлений, позволяющих повысить эффрективность бизнеса и снизить трансакционные издержки, связанные с поиском клиентов, ведением переговоров, подготовкой и организацией сделки, является цифровизация или уберизация. Уберизация или юберизация (от названия компании Uber) - замена посредников (людей или организаций) цифровыми платфрормами. Цифровизация в самом общем плане - это внедрение новых цифровых технологий в качестве средства получения желаемого исхода, а именно гибкого производства, приносящего клиентам отличный результат, а владельцам - более высокую прибыль. Кроме гибкости и эффрективности процессы цифровизации и уберизации бизнеса обеспечивают возможность получения большого количества дополнительной информации, в том числе маркетинговой. Целью данной статьи является изучение тенденций цифровизации туристического бизнеса путем внедрения мобильных приложений и использование преимуществ цифровых технологий в маркетинге. Объект исследования - процессы цифровизации и уберизации туристического бизнеса, предмет исследования - маркетинговые возможности и особенности в современном туристическом бизнесе.

Относительно такого сектора, как туризм, отметим, что он подвержен процессам цифровизации и уберизации, ведётся активная работа по внедрению и адаптации цифровых технологий, в частности мобильных приложений для оптимизации туристического бизнеса и повышения качества услуг для клиентов. По некоторым оценкам, около $75 \%$ туристов используют как минимум одно мобильное приложение во время своей поездки. Мобильные приложения для путешествий занимают 7-ое место по количеству скачиваний среди всех существующих приложений [1]. 
Мобильные приложения для туризма представляют ценность и для потребителей туристического продукта (сегмент «В2С»), и для его поставщиков, и для предприятий родственных и поддерживающих отраслей, входящих в туристический кластер (сегмент «В2В»).

Некоторые принципиальные подходы мобильному приложению как к продукту уже изложены в современных исследованиях [2], но они могут быть уточнены применительно к туристическим приложениям:

1. Правильная фокусировка на неудовлетворенной потребительской потребности, которая обеспечивает необходимость возвращаться к использованию мобильного приложения на регулярной основе. Например, для туристов (сегмент «В2С») это такая неудовлетворенная потребность - возможность быстрого поиска попутчиков и профессионалов для обеспечения конкретного путешествия в соответствии с задуманной идеей. Такую потребность может удовлетворить бесплатное приложение-агрегатор. Для представителей туристического бизнеса (турфирм, отелей, продавцов специализированных сопутствующих товаров и услуг - сегмент «В2В») такая неудовлетворенная потребность возможность привлечения клиентов благодаря размещению своего продукта в приложении. Клиенты названных секторов будут возвращаться к приложению, если оно имеет для них постоянную ценность, а не потому, что этого желает разработчик. Очень важно принять это с самого начала и ответить на вопрос: зачем кому-то использовать приложение?

2. Лаконичность и простота интерфейса. При этом имеется в виду не упрощение функционала программы, а обеспечение легкости в использовании приложения. Приложение должно предоставлять доступ ко всему перечню функциональных возможностей, предусмотренных программой, без ущерба для простоты работы. Один из возможных путей поддержания простоты - представление на экране информации, минимально необходимой для выполнения пользователем очередного действия в приложении. Необходимо понимать, что пользователю неудобно вводить на мобильном устройстве столько же информации, сколько на настольном компьютере. Необходимо использовать преимущества маленького экрана, позволяющие сосредоточиться на самом главном.

3. Обратная связь (feedback). Требуется подумать о создании встроенных в приложение инструментов связи, чтобы обеспечить отправку отзывов внутри приложения. В приложении для туризма для сбора и анализа отзывов: о турпродукте (туре, инструкторах, размещении и т.д.), позволит слушать клиентов, прежде чем они достаточно расстроятся, чтобы удалить приложение. рентабельность инвестиций в сервисы обратной связи значительна так, как они помогают гибко реагировать на любые запросы потребителя и дают возможность персонифицированного подхода при предложении турпродукта. Использование мобильных приложений в туристическом бизнесе дает возможность быстро проверять гипотезы о поведении пользователей в ответ на те или иные 
инициативы благодаря обратной связи (feedback) со всех своих пользователей. Применительно к туристическому рынку могут быть собраны данные о целевой аудитории и особенностях спроса во всех элементах туристического кластера. Например, предпочтения по всему спектру туристических продуктов, сезонные колебания спроса, эластичность (чувствительность) спроса к различным маркетинговым мероприятиям: рекламе, акциях и т.д. Для маркетологов мобильное приложение - очень мощное место для общения с целевой аудиторией.

Следующей достаточно обширной областью для обдумывания является проблема удержания клиентов, ведь много установок (скачиваний) - еще не гарантия успеха. Важность удержания уже существующих клиентов очевидна, ведь в соответствии с канонами маркетинга, клиент, ожидания которого были обмануты, больше не вернется. Для эфффективности бизнеса большое значение имеют постоянные клиенты. Затраты на их удержание ниже, чем на привлечение новых. Поэтому, чем жизненный цикл клиента длиннее, тем бизнес рентабельнее.

Емкость и широта названной проблемы требуют довольно глубокой разработки, в рамках данного исследования кратко обозначим лишь некоторые умозаключения:

1. Для удержания клиентов в сегменте «В2С» важно правильно сформировать их представление о предоставляемой услуге и в некоторой степени превзойти их ожидания, это обеспечит запас лояльности к бренду компании. Лояльный клиент обязательно расскажет о приложении своим знакомым и будет сам использовать его повторно. Цифровые инструменты позволяют показывать клиентам именно ту рекламу, которой они заинтересуются, следить за передвижениями на сайтах и запросах в поисковике, могут создавать все больше поощрений для пользователей, чтобы те заходили чаще в приложение.

2. Обеспечение высокого уровня профессионализма. Люди прислушиваются к мнению профессионала своего дела и пользуются их услугами вновь и вновь. Профессионал в своей сфере, который постоянно развивается и разбирается в новейших трендах, не останется без клиентов. В частности, говоря о туристическом приложении, правообладатели такого бизнеса должны быть готовы не только агрегировать предложение поставщиков туристического продукта, но и брать ответственность за его качество и за размещенный контент.

3. Мониторинг индекса потребительской лояльности (Net Promoter Score или NPS), который будет показывать, сколько у приложения сторонников или промоутеров - людей, готовых рекомендовать приложение своему окружению. Предложение вычислять индекс потребительской лояльности было выдвинуто его разработчиками в 2003 году и поддерживается современными маркетологами [3]. Процесс его исчисления основан на ответе на вопрос: «Насколько вероятно, что вы порекомендуете нас?»; Клиенты отвечают по шкале от 0 до 10, где 0 - ни за что не порекомендую, а 10 - порекомендую обязательно. По отве- 
там распределяют сегменты: критики, нейтралы и промоутеры. Клиенты, ответившие от 0 до 6, составляют сегмент критиков, от 7 до 8 - нейтралов, от 9 до 10 - сторонников или промоутеров. Далее из доли в процентах сторонников вычитают долю в процентах критиков - это и есть NPS.

4. Использование подходов unit-экономики - инструмента, который позволяет оценить прибыльность проекта через прибыльность конкретной единицы (одного клиента). Одно из ключевых понятий unit-экономики - LTV (lifetime value) или прибыль от клиента за весь его жизненный цикл, который равен периоду между датами первой и последней покупки.

5. Доверие и поддержка - это основа современного бизнеса, маркетинг отношений в последнее время становится все популярнее, а выстраивание отношений с клиентом на фундаменте доверия и поддержки укрепляет бизнес. Классическим примером такого подхода является персонифицированная система скидок, бонусов и продвижения в рейтинге, что очень актуально и реализуемо именно на базе использования цифровых технологий. Кроме перечисленного, применительно к теме исследования необходимо показывать клиентам, размещающим свои туристические продукты в приложении (сегмент «В2В») интерес к их бизнесу, выстраивать и развивать долгосрочные взаимовыгодные отношения.

\section{ЛИТЕРАТУРА}

1. Володченко В.С., Ланцова Д.С., Миронова Т.А., Бышок К.А., Сапунова Е.В. Анализ рынка мобильных приложений в туристской индустрии // Вопросы науки и образования 2020. №33. С. 109-113.

2. Семенов И.О., Мун Д.Е. Пять самых больших ошибок в маркетинге мобильных приложений // Colloquium-journal. 2019. №13-2 C. 204-205.

3. Интернет-агентство «Текстерра» [Электронный ресурс]. [сайт]. [2007]. URL: https://texterra.ru/blog/nps-indeks-potrebitelskoy-loyalnosti-kotoryy-nuzhnootsle zhivat-kazhdoy-kompanii.html. (дата обращения: 24.04.2021). 